\title{
LOS DISPARATES DE CALDERÓN ${ }^{1}$
}

Ignacio Arellano

Departamento de Literatura Hispánica

Facultad de Filosofia y Letras GRISO-Universidad de Navarra 31080 Pamplona. Navarra. España iarellano@unav.es

[Anuario calderoniano (ISSN: 1888-8046), 3, 2010, pp. 37-66]

Calderón, hombre (TAmbién) De Burlas

A propósito del centenario de la muerte de Calderón en 1981, comentaba el insigne calderonista, Kurt Reichenberger, en un artículo que titulaba «Calderón ¿persona non grata?», que la prensa madrileña en general exhibió una actitud hostil contra el poeta, y se lo explicaba por el cultivo de cierta imagen de un Calderón severo e inquisitorial, viejo ceñudo, hombre de mal humor, atenido a los dramas de honor truculento y a los adoctrinamientos más reaccionarios. Esta imagen se ha ido erosionando con los estudios de las últimas décadas, aunque el universo calderoniano queda todavía por explorar en su mayor parte.Y precisamente es el Calderón cómico el que seguramente necesita de mayor asedio.

En esta exposición intentaré un somero repaso de una modalidad de mecanismos burlescos a los que Calderón se muestra notablemente aficionado desde sus piezas más tempranas, e incluso en la práctica

1 Este trabajo cuenta con el patrocinio de TC-12 en el marco del Programa Consolider-Ingenio 2010, CSD2009-00033, del Plan Nacional de Investigación Científica, Desarrollo e Innovación Tecnológica. 
de su ingenio personal, según recogen algunos anecdotarios del Siglo de Oro. Me refiero al género de los disparates, que se rastrean en toda la obra calderoniana, especialmente, como es sabido, en la comedia burlesca de Céfalo y Pocris, pero no solamente en ella.

Al parecer fue Calderón inclinado a los ingeniosos disparates de repente, propios de las fiestas y certámenes, como los celebrados en 1637 en el Buen Retiro ${ }^{2}$. Sea descripción de un suceso real o ficción de Francisco de Rojas - autor de una parte del vejamen que cerraba la Academia correspondiente-, interesa el dato por lo que evoca de don Pedro ${ }^{3}$. Entre la serie de burlas y chistes aplicados a un elenco de poetas participantes aparece Calderón probándose la cabellera de Rojas, cuya calva era bien conocida, y haciendo juegos de palabras absurdos:

Venía don Pedro Calderón en medio probándose a un espejo mi cabellera, pero viendo que no le asentaba, la arrojó diciendo:

No me la quiero poner que a mi desgracia recelo

que no la ha de cubrir pelo.

Hizo parar el carro de la mojiganga Andrés de Borgoña con un papel del señor protonotario en que le encargaba que hiciese una comedia de capa y espada para el servicio de su majestad y que tuviese grandes pasos, y don Pedro Calderón respondió con esta redondilla:

Si pasos de más primores

buscáis para tales casos

yo escribiré vuestros pasos

que no pueden ser mayores.

El ingenio repentista que muestra el relato es propio de los divertimentos de academias jocosas, y las fiestas del Retiro de 1637 y 1638 son muy ricas en este tipo elementos improvisados, sin que falten en ellas comedias burlescas, género que sin duda se relaciona con esta téc-

${ }^{2}$ Ver Academia burlesca, estudio de Teresa Julio para las circunstancias y textos de la Academia burlesca que corresponde a estas fiestas del Retiro para honrar a la visita a Madrid de la princesa de Carignan y celebrar el nombramiento de Fernando III como Rey de Romanos.

3 Academia burlesca, p. 228. 
nica de la improvisación disparatada ${ }^{4}$. Por ejemplo, la comedia de Escarramán, atribuida alguna vez a Moreto, y representada en el carnaval de 1638, si Kennedy ${ }^{5}$ está en lo cierto, según confirma una noticia de las Cartas de jesuitas, fue una comedia improvisada sobre un esquema que se les había dado a los representantes previamente.

De esta categoría fue otra comedia de la que solo conservamos escasas referencias, en la que participó Calderón, completando otras actuaciones en certámenes burlescos, según una gaceta de la época, que da noticia de que el viernes 19 de febrero

hay en el salón en presencia de su majestad academia de poetas, que de repente, incitados de un furor poético, han de hablar versos sobre las materias propuestas. Refieren que dos de ellas son «¿Por qué a Judas pintan con barba rubia?» y «¿Por qué a las mujeres o criadas de palacio llaman mondongas, no vendiendo mondongo?». Espérase que Luis Vélez y don Pedro Calderón serán los que más se señalarán ${ }^{6}$.

Vélez y Calderón debían de ser dos notables participantes en estas diversiones jocosas y ambos desempeñan papeles protagonistas en la comedia burlesca y de repente titulada La creación del mundo, según documenta el portugués Pedro Jose Suppico, en sus Apotegmas politi$\cos y$ morales $^{7}$. Entre otros personajes de cuyo desempeño no tenemos noticia hacía de Padre Eterno Luis Vélez, de Adán Calderón y de Abel Moreto.

Al parecer Calderón había sustraído unas peras a Vélez, y en una de las improvisaciones de la comedia, representada ante Felipe IV, recitaron estos versos:

AdÁN

Padre Eterno
Padre eterno de la luz ¿por qué en mi mal perseveras?

Porque os comisteis las peras

y juro a Dios y a esta cruz

que os he de echar a galeras.

\footnotetext{
${ }^{4}$ Ver Arellano, 2002.

5 Kennedy, 1941.

${ }^{6}$ Ver en Rodríguez Villa, 1886, p. 103.

${ }^{7}$ Ver Cotarelo, 1924, p. 183; Kennedy, 1941, pp. 116-17; Lacadena, 1988, pp. 97-
} 98. 
Como Adán (Calderón) siguiera disculpando el hurto de las peras con un parlamento demasiado largo, Vélez, es decir, el Padre Eterno, cansado de oírlo y de sostener en la mano el globo del mundo, lo arrojó al suelo diciendo:
Por Cristo crucificado
que, como soy pecador, me pesa de haber criado
un Adán tan hablador.

O según otra versión menos disparatada, y seguramente pulida por razones censorias:
Por el cielo superior
y de mi mano formado, me pesa de haber criado un Adán tan hablador.

Seguía una escena amorosa entre Adán y Eva —no sabemos quién hacía de Eva-, con los requiebros consiguientes:

-Eva, mi dulce placer, carne de la carne mía.. —Adán, mi bien y alegría...

diálogo interrumpido por Moreto, que asomado a la cortina completaba la redondilla: «Estos me quieren hacer».

La propensión calderoniana al disparate se manifiesta también en el romance de autorretrato jocoso que comienza «Curiosísima señora» ${ }^{9}$. Pertenece esta composición a otra moda aurisecular de autorre-

${ }^{8}$ Es la que cita Cotarelo, 1924, p. 183, nota 1.

${ }^{9}$ Ms. 3797 de la Biblioteca Nacional de España y otros testimonios. Una versión publicó Hartzenbusch. Ver Cotarelo, 1924, pp. 66-70 especialmente. Modernamente lo estudia A. de la Granja, 2003, y antes, 2000. Wilson lo atribuyó a Carlos Alberto de Cepeda y Guzmán, pero con mejores razones de la Granja lo atribuye a Calderón. Ya discutía la atribución a Cepeda Cotarelo. 
tratos burlescos de poetas ${ }^{10}$. Se suceden en el romance las perogrulladas y otras modalidades de disparate:

\author{
Yo soy un hombre de tan \\ descomunal estatura \\ que entre los grandes es poca \\ y entre los chicos es mucha. \\ $[\ldots]$ \\ Mis manos son pies de puerco \\ con su vello y con sus uñas: \\ que, a comérmelas tras algo, \\ el algo hicieran grosura. \\ Mi talle, si gusta el sastre, \\ es largo; mas si no gusta \\ es corto; que manda desde \\ mi golilla a mi cintura; \\ [...] \\ gorrón, poeta, escudero \\ fui, soy y seré. ¡Oh, suma \\ paciencia de Job!, ¿tuviste \\ más calamidades juntas?
}

El catálogo de disparates calderonianos tiene algunos territorios especialmente aptos para su acumulación, sobre todo en el discurso de los graciosos de las comedias, en el entremés y en la comedia burlesca.

\title{
Disparates en las comedias
}

La modalidad jocosa de los disparates ${ }^{11}$ se halla dispersa, pero constante, en los discursos de los graciosos de comedia. En los géneros trágicos el gracioso es el único agente especializado de la comicidad, por lo que solo a él puede corresponder la práctica del disparate. En las comedias cómicas los agentes de la risa se generalizan, pero el tipo de

10 Tienen ejemplos Lope, Góngora, Pantaleón de Ribera, Polo de Medina, Trillo y Figueroa, Castillo Solórzano, Catalina Clara Ramírez de Guzmán, etc. Ver Arellano «Filomocosías áureas», en prensa.

${ }^{11}$ Ver para el género Periñán, 1979. 
comicidad absurda sigue perteneciendo a los graciosos, con algunos ensayos en los casos de figurones como don Toribio Cuadradillos de El agua mansa.

Ya en comedias tempranas como Judas Macabeo (p. 20) ${ }^{12}$, aparece un gracioso (Chato) con la disparatada exigencia de ser ahorcado para que se pueda luego quejar a Zarés de lo mal que tratan a sus criados:
me han de ahorcar
y después de ahorcado yo
diré a Zarés de la suerte
que a sus criados dan muerte
sin decirle sí ni no...

En el corpus calderoniano se acopian todas las variedades de disparates desde las contradicciones lógicas como en La fiera, el rayo y la piedra (p. 1596) donde los graciosos Pasquín y Lebrón quieren huir de una fiera salvaje (Irífile), pero sin mucha fatiga («—Pues corramos. Norabuena, / pero corramos sentados») a los imposibles resueltos mediante un juego de palabras como el de Duelos de amor y lealtad (p. 1490), en donde Morlaco reclama a Flora que le agradezca el haberla hecho más moza que era antes. ¿Cómo es posible que sea más moza hoy que ayer? Por haber entrado a su servicio como criada o moza:

Claro está, porque ¿qué dama
que envejece siendo ama
si se entra a servir no es moza?

El chiste en este caso es tradicional y entre otros lo aplica Quevedo ${ }^{13}$.

También es tradicional el disparate del tonto Rústico en Celos aun del aire matan (vv. 2098-2100) que pide a Clarín que lo considere «el menor marido / de esta señora». El chiste gustó mucho a Calderón, que lo usa en La señora y la criada (en boca de Perote), La aurora en

12 Cuando indique la página significa que cito las comedias y dramas de Calderón por las ediciones de Valbuena en Aguilar que recojo en la bibliografia. Si indico versos me referiré a las ediciones cuyos datos se recogen igualmente en la bibliografia.

13 Está en la Floresta española de Melchor de Santa Cruz, La viuda valenciana de Lope, La Pícara Justina, Covarrubias, etc. Ver Chevalier, 1976. 
Copacabana (Tucapel), El pastor Fido (Sátiro), y en el entremés de El dragoncillo. Como recuerda Chevalier es chiste epistolar repetido con variantes en los textos del Siglo de Oro (Floresta española, Lucas Gracián Dantisco, Cervantes, etc. ${ }^{14}$ ).

Una modalidad privilegiada es la del vacío semántico de un discurso que carece totalmente de información, como las perogrulladas y otras tipologías: las explicaciones de Lebrón en La fiera, el rayo y la piedra (p. 1608) no aportan ninguna noticia, más allá de la inquietud del gracioso por los sucesos de la trama, inquietud que le impide formular un mensaje razonado:
Desde aquel infausto día ¡quién le borrara del tiempo! que en la fragua de Vulcano nos vimos todos revueltos también yo tengo mi poco de no sé qué, que le siento no sé dónde y no sé cuándo le he de aplicar el remedio.

Semejante es el caso de Bato (Fortunas de Andrómeda y Perseo, p. 1657), cuya información sobre dos casos bien espantosos que debe comunicar a Perseo y Dánae, es bastante precaria, si desechar la burla a los propios espectadores, a quienes califica de tintos y tontos:

De uno no me acuerdo
bien; mas del otro tampoco.
Y pues ya aquí los he dicho
voy a decirlos a otros,
que no hay cosa como andar
con sus nuevas de retorno
uno engañando a otros tantos,
a otros tintos y a otros tontos.

${ }^{14}$ Ver Chevalier, 1976. La versión de la Floresta es: «Escribiendo uno a su mujer, puso a par de la firma: "El menor marido de vuestra merced"». Lucas Gracián Dantisco, Galateo español: "Como un recién casado que escribió a su mujer una carta de muchos donaires, y concluyó poniendo en la cortesía de abajo: "Menor marido de V. m., que sus manos besa. Fulano"” (cits. por Chevalier). 
Es una categoría de discurso que hallaremos desarrollada en la comedia burlesca de manera sistemática. En Céfalo y Pocris, las quejas del rey, por ejemplo, son dos o tres:

\author{
Es la primera \\ esta, la segunda la otra \\ y la tercera es aquella. (vv. 1107-1109)
}

Los paradigmas del pregón absurdo (El mayor encanto amor, p. 1528), de la serie hiperbólica (El mayor encanto amor, p. 1529; Antes que todo es mi dama, p. 882), o de la enumeración de invectivas (Apolo y Climene, p. 1850) son otras tantas exploraciones del disparate, que llegan a la estructura que se puede denominar vorágine verbal o a los diálogos cuya dislocación sintáctica evidencia la dislocación semántica. Ejemplos de unas y otras modalidades hay en El golfo de las sirenas (p. 1736), La púrpura de la rosa (p. 1770), Apolo y Climene (p. 1850), Auristela y Lisidante (vv. 3074-3080), Antes que todo es mi dama (p. 883), etc. Valga el ejemplo del parlamento de Alfeo (cuyo papel hizo Cosme Pérez, Juan Rana, en El golfo de las sirenas, p. 1736), hecho pescador de tierra:

Yo soy pescador de tierra
e ir al terrado conviene
tierra a tierra tan despacio
que me entierre en la terraza
de un terrado de la plaza
o un terrero de palacio
antes que de un terremoto
el terror que me sotierra
en soterraños de tierra
me dé sepulcro remoto
en el agua...

ULISES

Un loco es.

Alfeo

$\mathrm{Y}$ aun dos.

O el de Brunel en Auristela y Lisidante (vv. 3074-3080):

Brunel ¡Oh, Clarïana excelente!, patronímico desde hoy 
de clareas y claretes, serán cuantas Clarianas las claraboyas clareen de los presos Condes Claros...

Y un pasaje arquetípico de la desarticulación lingüística en este de Batillo (El hijo del Sol, Faetón) temeroso de la fiera que se dice haber visto en el monte:

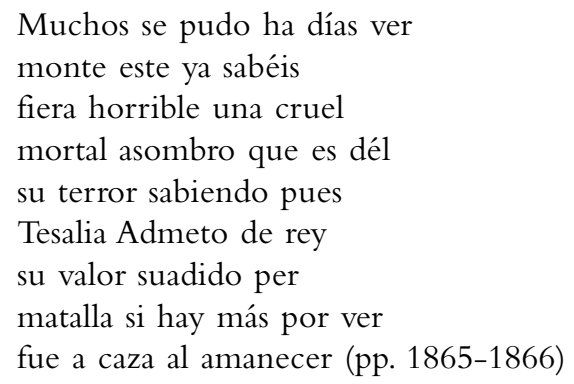

Los disparates verbales se asocian a los gestuales, prosémicos y en general de la escenificación, que llegan a su extremo en las metamorfosis grotescas, como las de Clarín, convertido en mona en El mayor encanto amor, o Rústico en Celos aun del aire matan convertido en un animal tetramorfo, con cabeza de león, lobo, tigre y oso, con la gesticulación correspondiente. No entraré en el detalle de estos medios escénicos que he estudiado en un trabajo anterior al que remito para más detalles ${ }^{15}$.

\section{Disparates en los entremeses}

El universo cómico, a menudo cercano al carnaval, de los entremeses ${ }^{16}$ y otras formas breves teatrales o parateatrales como bailes, pandorgas y mojigangas, es especialmente apto para la proliferación del disparate.

${ }^{15}$ Ver Arellano, 1986.

16 Cito los entremeses por la ed. de Lobato de Teatro cómico breve recogida en la bibliografia, indicando la página. 
En la Premática ( $2^{a}$ parte) se integra un motivo asociado al mundo al revés en el galanteo de María a Nicolás, en una inversión de papeles que implica una parodia de las fórmulas dramáticas vigentes sobre todo en el género de capa y espada:

María Esta es la reja, hacer la seña quiero.

De presumir que ha de enojarse muero

de temor. ¡Cuánto pasa quien bien ama!

Nicolás a la ventana.

Nicolás ¿Quién a mis rejas tales horas llama?

María Yo soy, mi bien.

NiCOLÁs

¿Hay tal osado intento? (p. 54)

Otra modalidad de estas inversiones constituyen el esquema básico de una de las mejores piezas breves calderonianas, la Mojiganga de las visiones de la Muerte, que explota la dislocación entre el vestido y el lenguaje: los actores de una compañía que se dirigen a un pueblo a representar un auto sacramental y van vestidos con sus trajes de teatro, vuelcan al cruzar un río. A los ojos de un caminante borracho y adormilado aparecen un diablo rezador santiguándose, un ángel jurador, un Alma en brazos del Cuerpo, una tropa de gallegos huyendo de unos gitanos, y otras visiones absurdas:

Demonio jJesús mil veces!

Hombre, quien quiera que seas, gracias a Dios que te encuentro.

Caminante Buen cristiano es este diablo... (p. 357)

Todo acaba en libaciones generalizadas de la bota del caminante y en un alboroto de mojiganga.

El disparatar adrede caracteriza a los entremeses relacionados con las diversiones carnavalescas. Una pieza particularmente interesante es $E l$ sacristán mujer, escrito, según una nota del ms. 15197 de la Biblioteca Nacional de España, para María López, que hace el papel de Aura en la comedia burlesca de Céfalo y Pocris ${ }^{17}$. El entremés muestra algunas

${ }^{17}$ Ver infra en el comentario de Céfalo y Pocris la relevancia de este dato para la datación de la comedia. María López muere en 1651; el entremés se suele fechar en- 
concomitancias curiosas con la citada comedia: la cancioncilla de San Cristóbal, muy parecida en ambas (vv. 218-22 de Céfalo y 105-108 del Sacristán), y los vv. 97-98, presentes también en Céfalo y Pocris, vv. 694695. En el entremés Brígida exige a quien quiera ser su marido una serie de habilidades (tañer, danzar, cantar, ser poeta, etc.), y María López, de sacristán, rivaliza con otros pretendientes. Todo el esquema de la pieza se basa en el disparate, desde el latín macarrónico del sacristán mujer («Ese sum ego, / ego sum, Brígida mía, / ego sum, dulcis requiebrum, / generalis licenciatus / in dancis, in zapateus, / in arparum que ticatum, / in canticis et in versus. / Date mihi manum blanca», pp. 112-113). Cada pretendiente exhibe sus habilidades: el sacristán (no María, sino otro personaje) recita el romance de «Apacible basilisco", típica composición disparatada (pp. 113-114); Josefa representa como ciego un poema de arte mayor a San Cristóbal que «estaba a la puerta / de la ribera del mar caudaloso / para pasar cierto niño gracioso / con su bastón y capilla cubierta» (p. 115); Mari López hace glosas de pie forzado a los ojos, nariz, boca y manos, de cuyo estilo valga la muestra de la nariz:

\author{
Nariz de blanco perfil \\ que hace afrenta al marfil, \\ hoy en tu limpieza toco, \\ que eres exenta de moco \\ como moco de candil. (pp. 116-117)
}

Y termina Mari López su demostración con un soneto burlesco de rimas agudas en $-\mathrm{oz},-\mathrm{iz},-\mathrm{az},-\mathrm{uz}$, otra forma usual en las comedias burlescas, que supone además una elaborada parodia de la técnica de la diseminación recolectiva, ya que el soneto recoge los motivos glosados antes de la boca, ojos, nariz y manos:

Boca más sazonada que el arroz y más recta que un juez blanca nariz, manos más blancas que la regaliz y ojos más segadores que una hoz... (p. 117)

tre 1644 y 1650 , cuando María actuaba en la compañía de su padre, citado igualmente en Céfalo ("yo soy hija de Luis López», v. 415). La comedia podría ser de fechas semejantes al entremés. 
Al final descubre María su verdadera identidad de mujer y acaban con un baile paródico de bodas: «La doncella y el infanzón / para en uno son».

En realidad el tejido de este entremés se acerca mucho a la técnica de conglomerado de parodias poéticas y dramáticas que caracteriza en buena parte a la comedia burlesca, al menos en la fórmula calderoniana de Céfalo y Pocris.

Plenamente carnavalescos son otros entremeses como el de La pandera, Los guisados y Carnestolendas. En La pandera sufre don Gil Catiborratos una serie de burlas de carnaval que le hacen unos matachines, y unas figuras ridículas (negro, moro, sayón) que lo insultan y lo van a mantear cuando aparece un alguacil. La pandera le explica que todo es burla de mojiganga y que los disparates son la condición precisa del género:

\author{
disparates adrede \\ puestos en chanza \\ cosas son a que obligan \\ las mojigangas. (p. 629)
}

En Los guisados, aparte de otras invenciones, se puede reconocer la pelea de don Carnal y doña Cuaresma en el torneo de los guisados y peleas de don Jigote y Carnero Verde con el Estofado, o los desafios de don Mondongo en defensa de la belleza de su amada doña Chanfaina Livianos. Armas como cucharones, asadores, palos de canela, y empresas heráldicas hechas de morcillas y manos de cerdo se despliegan en una estupenda parodia disparatada presidida, como no podía ser menos, por el dios Baco y la Olla podrida vencedora.

En Las carnestolendas (pp. 433 y ss.), que por su propio tema específico es el entremés que más densidad muestra de elementos del carnaval, se suceden un vejete, un negro, el rey que rabió ("Sale uno con una corona de rey y una mano de mortero por cetro»), un hombre «la mitad de mujer y la otra mitad de hombre, puesto al revés y andando hacia atrás», y la famosa dueña Quintañona "con gorra chata, cuellecito y ropa antigua, basquiña vieja y escurrida», y bailan entre ellos: es evidente desde el mismo título la presencia de los motivos carnavalescos, como el mundo al revés y la figura de un «rey de locos» grotesco que lleva por cetro una mano de mortero (p. 441). 
Análogos bailes se hallan en Céfalo y otras obras. Juegos y comidas de carnaval (p. 435) proliferan en la brevedad de la pieza: persecuciones con maza del gracioso a Luisa, actos grotescos de comer y beber, mascarillas, peleas de borrachos, parodias de fiestas de toros, juego de gallos, y para finalizar el consabido alboroto de la pandorga, construyen este entremés que debe parte de su estructura al Sueño de la muerte de Quevedo, con la serie de apariciones de figurillas del refranero o tipos folklóricos.

Una modalidad de disparate verbal omnipresente en los entremeses, propiciada por la frecuencia de figuras grotescas con sus respectivos discursos, es la de las jergas macarrónicas y las alteraciones de idiomas - francés en La franchota, italiano en La barbuda (1. $\left.{ }^{a}\right)$, de moros y negros, o tudescos borrachos en Carnestolendas y La pandera-, o de fórmulas como la del conjuro en El dragoncillo y La rabia $\left(1 .^{a}\right)$. Este es por ejemplo el conjuro del saludador en el último entremés citado:

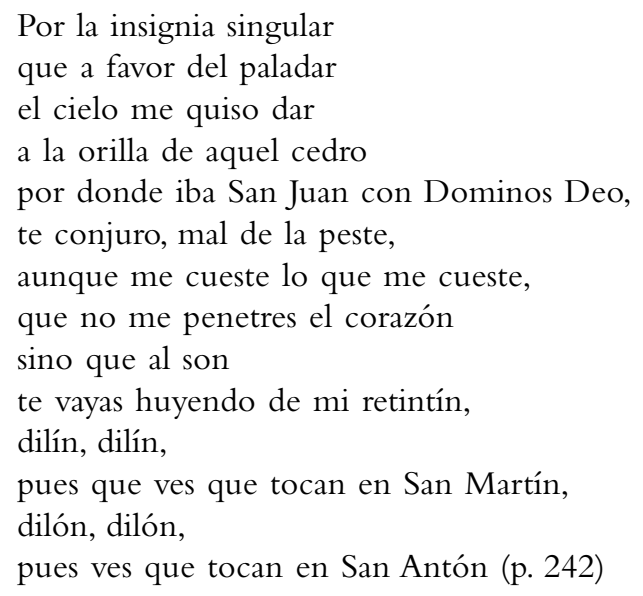

No solo se explota el efecto disparatado, sino que a menudo se integran otras connotaciones burlescas, como las escatológicas en la jerga de negros que imita al gracioso de Carnestolendas:

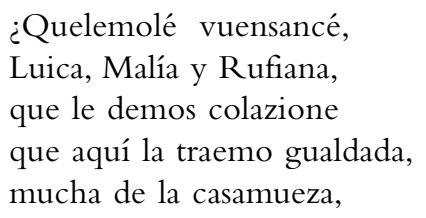


mucha de la cagancaña, cagalón e cochelate, calamerdos, merdaelada turo para vuesancé? (p. 439)

El entremés es género destinado a la diversión cómica, y estriba de manera decisiva en el concepto de la turpitudo et deformitas, que se lleva al extremo en la comedia burlesca, llamada a veces significativamente comedia de disparates, también cultivada por don Pedro Calderón.

\section{Calderón y la comedia burlesca. Céfalo y Pocris}

Según podemos deducir de algunas escasas referencias, no siempre seguras, Calderón debió de escribir al menos tres comedias burlescas, de las que solo se conoce hoy Céfalo y Pocris.

Poco sabemos de la que tituló La Celestina. La presencia de la obra de Rojas en el teatro del Siglo de Oro es irregular ${ }^{18}$. Solo conozco dos obras posteriores a Lope que a primera vista parecieran centradas de modo directo en la imitación de La Celestina: la aludida de Calderón, que figura en la lista de sus comedias que él mismo envió al Duque de Veragua, y La segunda Celestina o El encanto es la hermosura, de Agustín de Salazar (con participación de Sor Juana Inés de la Cruz). A juzgar por los rastros de otras imitaciones literarias calderonianas (también perdidas como la comedia de Don Quijote de la Mancha de la que hablaré enseguida) creo que esta Celestina podía haber sido una comedia burlesca. La hipótesis se refuerza si se tiene en cuenta la tendencia general de las adaptaciones o imitaciones de Rojas en la comedia aurisecular, evidente en la pieza de Salazar, que tiene muy poco de celestinesco propiamente dicho, y constituye una desviación arquetípica hacia lo cómico y caricaturesco, todavía más acusada en las versiones entremesiles como las del Entremés de la hechicera (atribuido alguna vez a Lope) o La vieja Muñatones de Quevedo.

Más datos tenemos de otra comedia perdida de Calderón titulada Don Quijote de la Mancha o, según otros testimonios, Los disparates de

${ }^{18}$ Ver Arellano, 2001. 
don Quijote, que Vera Tassis pensaba incluir en la nunca publicada Décima parte de comedias de Calderón ${ }^{19}$.

Sabemos, por distintos documentos, que se estrenó en palacio en 1637, en las fiestas ya comentadas a la venida de la princesa de Carignan. Se representó de nuevo como "comedia vieja» en el carnaval de 1673 , lo cual confirma su categoría burlesca ${ }^{20}$.

Sobre este texto perdido los estudiosos han apuntado algunas observaciones que quizá convenga matizar. Sánchez ${ }^{21}$ lamenta su pérdida, ya que en ella tendríamos el testimonio más directo de la influencia cervantina y "conoceríamos la interpretación calderoniana del ingenioso hidalgo", la cual supone de gran densidad poética y hondura caracterológica. López Estrada ${ }^{22}$ le atribuye un lugar entre las pocas que interpretarían con seriedad la obra de Cervantes, que serían en realidad solo dos, la de Guillén de Castro y, supone, esta de Calderón.

Aunque no conocemos la comedia, existen las suficientes pistas para estar bastante seguros de que ni Sánchez ni López Estrada aciertan al suponerla seria. Era sin duda una comedia burlesca o de disparates (como indica uno de los título que se le atribuyen), y que habría de reflejar una interpretación puramente jocosa y sin mayor preocupación por la coherencia argumental, de las aventuras de don Quijote. Todos los datos paralelos que pueden aducirse apuntan en esa dirección. La comedia de Guillén de Castro, por ejemplo, titulada Don Quijote de la Mancha, que es para López Estrada una comedia seria, merece una precisión: la parte seria trata la historia de Cardenio, mientras que las apariciones de don Quijote son siempre apariciones burlescas de un personaje figura, es decir, ridículo. Versiones ridículas son también las de piezas menores como el Entremés famoso de los invencibles hechos de don Quijote de la Mancha de Francisco de Ávila, la mojiganga Don Pascual del Rábano, o la comedia de disparates Aventuras verdaderas del segundo don Quijote, de un tal Castillo, citada por Rius, y mencionada, como las otras, en el trabajo de López Estrada.

${ }^{19}$ Ver Arellano, 1999.

${ }^{20}$ Ver Cotarelo, 1924, pp. 182-184 y 324, y Wilson, 1982, p. 10. Calderón la cita en la lista de sus comedias que envió al duque de Veragua en 1680, y en otra anterior entregada por don Francisco Marañón a Carlos II.

21 Sánchez, 1957, p. 270.

${ }^{22}$ López Estrada, 1982, p. 323, y nota 96. 
Ridículas son las apariciones de don Quijote y Sancho en las fiestas y mascaradas que conocemos ${ }^{23}$, como la descrita por Pinheiro da Veiga y celebrada en Valladolid en 1605, en la que ya aparece un don Quijote con un sombrero grande en la cabeza y una capa de bayeta batiendo las ijadas a un pobre cuartago sucio con mataduras; o la que describe Salazar de las fiestas que hizo el Colegio de los jesuitas de Salamanca en la beatificación de Ignacio de Loyola.

Todas estas presencias quijotescas pertenecen a modelos carnavalescos y ridículos, y revelan un tipo de lectura cómica constante que nos permite inferir, por vía indirecta, pero con bastante probabilidad, el tipo de obra que era la perdida comedia de Don Quijote de la Mancha de Calderón.

Sea como fuere la única comedia burlesca de Calderón cuyo texto ha llegado hasta nosotros es Céfalo y Pocris.

La tradicional atribución de esta comedia burlesca a don Pedro Calderón de la Barca se ha puesto alguna vez en entredicho ${ }^{24}$, creo que sin fundamento justificado. Desde la primera impresión de la obra por don Juan de Vera Tassis en la Novena Parte de Comedias de Don Pedro Calderón, año de $1691^{25}$, todas las ediciones posteriores mantienen la autoría de Calderón, en pro de la cual resulta significativo que Vera Tassis no mencione ningún problema referente a Céfalo $y$ Pocris, en un prólogo dedicado precisamente a esclarecer este tipo de cuestiones sobre las comedias que contienen la Novena Parte y en el que comenta las deturpaciones que afectan a algunas comedias en concreto.

Céfalo y Pocris es una de las comedias burlescas más estudiadas por la crítica, lo que me eximirá de comentarios más detallados de algunos de sus aspectos, pero quedan algunos problemas aún pendientes, empezando por la datación.

La mayoría de los críticos han propuesto una datación basándose en dos datos erróneos, uno el de la relación de Céfalo con Celos aun del aire matan y Auristela y Lisidante —relación que a mi juicio es in-

23 Ver Lobato, 1994; Torres, 1999; Arellano, 2005.

${ }^{24}$ Valbuena Briones, 1965, p. 325.

25 Novena Parte de comedias del célebre poeta español, Don Pedro Calderón de la Barca [...] que nuevamente corregidas publica Don Juan de Vera Tassis y Villarroel [...], en Madrid, por Francisco Sanz [...], año de 1691. 
existente-, y otro el de una cita de Cotarelo mal hecha por Alberto Navarro, y que se ha transmitido a la bibliografia posterior. Se ha hecho así depender la fecha de Céfalo de la de Celos aun del aire matan, a la que se atribuyen, por otra parte, distintas dataciones.

Hartzenbusch en su Catálogo cronológico, había sugerido ya la fecha de 1662:

Céfalo y Pocris es una parodia de Auristela y Lisidante y Celos, aun del aire, matan, representada al otro día que estas, en un carnaval. Celos, aun del aire, matan está en la Parte diez y nueve de comedias escogidas, que tiene licencia del Ordinario, dada en 18 de octubre de 1662: así, ninguna de las tres comedias es posterior al carnaval de dicho año.

Modernamente Íñiguez Barrena ${ }^{26}$ asegura — sin aportar otra documentación- que

Céfalo y Pocris no es sino remedio burlesco de Auristela y Lisidante [...] Mayor es la relación que guarda con Celos aun del aire matan, fiesta cantada que se representó en el Coliseo del Buen Retiro el día 5 de diciembre de 1662 [...] La parodia por tanto tuvo que ser posterior, muy probablemente se hizo en el carnaval siguiente, o sea, en 1663.

Elena di Pinto $^{27}$ opina que Céfalo se debió de llevar a escena al día siguiente de Auristela y Lisidante y Celos aun del aire matan, que según Hartzenbusch se representaron el 5 de diciembre de 1660. Cree que pueden confirmar este dato los versos ${ }^{28} 263-265$, los cuales podrían referirse a la comedia seria representada el día anterior. Pero esos versos no se refieren a la comedia seria sino a una representación anterior de la propia burlesca, y de todos modos el 6 de diciembre no es carnestolendas, ocasión de la puesta en escena de Céfalo (ver la afir-

26 Íñiguez Barrena, 2001, p. 189. Pero Celos aun del aire matan no es de 1662.

27 E. di Pinto, 2002, pp. 997-999.

28 «Pastel.- ¿Mi nombre sabes? / Tabaco.- Desde ayer. Pastel.- No me acordaba / de que ayer fuimos los mismos» (vv. 263-265); añádase este otro pasaje: «Rey.- Pues dadla... / Antistes.- ¿Qué? Rey.- Una fraterna. / Antistes.- En la comedia de ayer / no se hizo. Rey.- Que se haga en ésta. / ¿Hay más de pedir prestado / ese paso a otra comedia?» (vv. 984-989). 
mación inicial «Fiesta que se representó a Sus Majestades, día de Carnestolendas, en el Salón Real de Palacio", y v. 1351).

Borrego $^{29}$ también considera a Celos y algunas escenas de Auristela como fuentes directas de Céfalo, y sitúa la burlesca en 1661 o 1662, basándose en supuestos datos de Cotarelo, que aducíamos erradamente en nuestra edición (Arellano et al.).

En efecto, en nuestra edición de la comedia ${ }^{30}$, aunque manteníamos incierta su fecha, volvíamos a relacionar la burlesca con Celos, y dábamos a ésta la fecha de 5 de diciembre de 1660, citando mal a Cotarelo a través del error transmitido por Navarro, que comentaré enseguida.

En general las suposiciones citadas adolecen de varios defectos capitales: el básico es que — como intentaré mostrar a continuaciónno se puede considerar a Céfalo parodia precisa de Celos aun del aire matan ni de Auristela y Lisidante, de manera que no sirve relacionar estas piezas; por lo demás la fecha de Celos aun del aire matan es controvertida, pero se puede colocar con seguridad en junio de 1661, fuera de la época de carnaval en la que se representó Céfalo, lo cual desliga a ambas de manera indiscutible. Esta fecha segura de Celos no la ha manejado nunca la crítica en torno a Céfalo en lo que a mí se me alcanza, y lo que ha sucedido es que quienes nos hemos ocupado de la burlesca hemos ido extendiendo un error de la crítica anterior.

Conviene aclarar con más detalle el asunto de la fecha atribuida a Celos. Se suele repetir que Cotarelo la fecha el 5 de diciembre de 1660. Esto no es cierto. Es Alberto Navarro ${ }^{31}$ quien asegura que Cotarelo atribuye tal fecha a la citada comedia, pero Navarro no localiza el pasaje de Cotarelo en cuestión, pasaje que realmente no existe. Lo que dice Cotarelo ${ }^{32}$ es que para el carnaval de 1660 solo se conoce el título de una de las comedias de Calderón (Mujer, llora $y$ vencerás), y además la documentación relativa a una fiesta toda cantada que iba a representar la compañía de Diego Osorio, y esta fiesta cantada del 5 de diciembre de 1660, según Cotarelo, fue La púrpura

29 Borrego, 2002, p. 974.

${ }^{30}$ Arellano, García Valdés, Mata y Pinillos, pp. 30-31. Pinillos, 2002, p. 1107 recoge de nuevo este dato equivocado para sugerir la datación de Céfalo en 1660-1662.

31 Navarro, 1984, pp. 143-144.

32 Cotarelo, 1924, pp. 310, 312-313. 
de la rosa (no Celos) ${ }^{33}$. En el carnaval de 1661 (había de estrenarse el 28 de febrero, pero por necesidades de ensayos, se hizo el 1 de marzo) se representó, según Cotarelo, el Faetonte, y el mismo día hubo otra comedia que "quizá sería El castillo de Lindabridris».

Cotarelo, en suma, no da fecha para Celos aun del aire matan. Esta comedia en realidad, como notifica un documento italiano de la épo$\mathrm{Ca}^{34}$, se iba a representar en el carnaval de 1661, pero un accidente sufrido por la actriz Luisa Romero hizo retrasarla hasta el 6 de junio de ese año de 1661.

De modo que las circunstancias de Celos no sirven de nada para datar Céfalo y Pocris.

El único dato, que no se suele precisar, y que me parece más útil para este asunto es la participación de la actriz María López en la comedia con los papeles de Aura y Lesbia, compatibles en escena (vv. 415,2016 ). Según los datos conocidos ${ }^{35}$ María López muere en 1651 , de modo que esta debe ser la fecha ante quem de Céfalo.

La imitación directa de Celos y Auristela ha sido generalmente puesta de relieve, pero solo García Valdés ${ }^{36}$, y en menor medida di Pinto, han examinado esta relación. Sin entrar en el detalle de cada argumentación, y recopilando las semejanzas que sus estudios y otros han señalado, las fundamentales serían las siguientes.

a) El nombre de Polidoro en Auristela y Céfalo. A mi juicio es un dato irrelevante. Un gracioso en El mayor monstruo del mundo se llama Polidoro, y otro Polidoro hay en Hado y divisa de Leonido y Marfisa. El detalle es demasiado secundario para fundamentar ninguna estructura paródica sistemática.

33 Según Chaves, 2004, p. 281, esta representación del 5 de diciembre pudo ser una reposición, y la comedia quizá se estrenara en enero de ese año.

${ }^{34}$ Ver Chaves, 2004, pp. 287-288. El aviso de la nunciatura de 8 de junio de 1661 dice: «Si cominciò l'altro hieri a rappresentare l'opera in musica chiamata Procri nel gran teatro del Retiro, assistendovi sua Maestà non dal balcone ma del mezzo della Sala da basso per goder megglio delle machine e prospetive, invitativi gli ambasciatori dei prencipi..." (Chaves, 2004, pp. 317-318).

35 Ver DICAT, donde se recogen todas las menciones de esta María López, hija de Luis López. Para esta actriz se escribe al parecer el entremés calderoniano de $E l$ sacristán mujer. Como ya se ha dicho, entre 1644 y 1650 actuaba en la compañía de su padre.

36 García Valdés, 2001. 
b) el juego de la gallina ciega. Pero en Céfalo es diversión carnavalesca escenificada paródicamente y en Auristela es una pasajera mención verbal chistosa de Brunel (vv. 904-908).

c) vuelo de Aura y muerte de Pocris en Céfalo y en Celos. Provienen ambos motivos de la fuente común ovidiana. La burlesca no es parodia directa de la mitológica.

d) arranque de la comedia burlesca con caballo (asno) desbocado y naufragio, parecido al comienzo de Auristela, incluso con expresiones iguales, según subraya García Valdés. Esta sería la semejanza más importante desde el punto de vista de la imitación directa, pero no hay tales parecidos. En realidad los personajes despeñados y náufragos de Auristela no se encuentran. Lisidante escapa, tras matar al príncipe Polidoro en un torneo, en un caballo, pero no se desboca ni lo despeña. Lo deja atado a unas ramas (vv. 457 y ss.). Arsidas sí naufraga, y al llegar a tierra coge el caballo y las armas que ha abandonado Lisidante, lo que provocará una serie de identificaciones erróneas que sirven a la trama. Las expresiones de los náufragos de Auristela («Piedad, cielos»; «Cielos, favor», vv. 526, 542) se parecen a las de Céfalo («Piedad, cielos», vv. 46, 54; «Piedad, dioses», v. 50), pero también se parecen a las de escenas semejantes de naufragios (fórmula fija para las comedias caballerescas y de espectáculo palaciego) en El golfo de las sirenas («úpiter, piedad», p. 1724), Ni Amor se libra de amor ("Clemencia, cielos, clemencia», p. 1958), El monstruo de los jardines («Piedad, dioses», «Piedad, cielos», p. 1985), Amado y aborrecido («Piedad, dioses», p. 1688) $\mathrm{y}$ otras, de manera que constituyen formulismos que nada revelan sobre una relación directa.

e) imitaciones de discursos patéticos, entrecortados, paralelismos y otros rasgos de estilo. No hace falta señalar que este tipo de recursos se producen en numerosas obras de Calderón, y que la parodia es general de estas estructuras, sin que se pueda relacionar directamente con Celos y Auristela.

Poca cosa, como se podrá advertir, para considerar la burlesca imitación estricta de las otras dos. Como señala Pinillos ${ }^{37}$ este juicio parece más bien responder a un tópico crítico que se arrastra desde Hartzenbusch.

37 Pinillos, 2002, p. 1108. 
Los disparates de Céfalo y Pocris parodian numerosos aspectos del teatro del Siglo de Oro y en especial del calderoniano, que ya han sido tratados en la bibliografia dedicada a esta comedia, y que no volveré a detallar ahora ${ }^{38}$.

La historia patética de Céfalo y Pocris aparece en el libro VII de las Metamorfosis y Ovidio la trata también en el libro III del Arte de amar. Otros poetas del Siglo de Oro la trataron en sus creaciones: Jorge de Montemayor, Lomas Cantoral, Lucas Rodríguez, Agustín de Salazar....

Las aventuras de estos personajes de la leyenda y mitología se someten a la abrasión del detalle costumbrista, al registro ridículo y a la serie de disparates. Destaca de manera especial en el trazado paródico de Céfalo y Pocris la acumulación de referencias textuales que la constituyen en una comedia-centón, sobre todo de dos tipos de fórmulas: el Romancero y cancionero tradicional, sin dejar aparte los romances y canciones cultos debidos a poetas como Lope o Góngora, y por otro lado el repertorio paremiológico, explotado en la manipulación jocosa de refranes y discurso lexicalizado, que se aplica literalmente, se modifica, o se invierte en una galería inacabable de ingeniosidades y chistes grotescos. Es la modalidad de la glosa disparate, estudiada por Blanca Periñán ${ }^{39}$, entre otras variedades de la técnica.

Pero lo que me interesa en esta ocasión no es volver a este tipo de recursos, sino subrayar que la cualidad de comedia centón no se detiene en el plano verbal, sino que afecta a la estructura dramática y compositiva, y que fundamenta la parodia.

Pinillos ${ }^{40}$, con buen acuerdo, apunta que Céfalo parodia algunos géneros, como las comedias mitológicas y las novelescas o caballerescas, pero en realidad esta comedia se compone como un muestrario de los géneros y fórmulas dramáticas más notables en el corpus de Calderón, además de las evidentes que menciona Pinillos.

Desde el primer verso aparecen varios elementos significativos: la gruta, el caballo desbocado y el naufragio. Habría que hacer una pre-

${ }^{38}$ Recojo someramente algunas líneas de nuestra introducción para resumir muy generalmente algunos recursos que no entraré a comentar más largamente. El artículo de García Valdés, 2001 es especialmente interesante en su análisis de los aspectos paródicos. Para aspectos de la escenificación disparatada ver Arellano, 1986 y 2005b.

39 Periñán, 1979, pp. 38, 68.

40 Pinillos, 2002. 
cisión respecto al primero de ellos (la gruta). No se trata del género de gruta de Segismundo, como supone Pinillos y otros estudiosos ${ }^{41}$ gruta de comedias políticas y autos sacramentales, de valor simbólico- sino más bien del túnel, usado en tramas galantes, y que Calderón explota en El galán fantasma y Apolo y Climene, por ejemplo, que sirve a un galán para introducirse en el jardín de la dama. La caída del caballo (del asno en Céfalo) y el naufragio (de una carreta, según el modelo del mundo al revés y de los imposibles) parodian, en este caso, fórmulas propias de comedias de tema político y cortesano, y de las fiestas palaciegas, donde el naufragio y la caza (con numerosos caballos desbocados) son funciones fijas. Puede quizá advertirse una cercanía particular a La vida es sueño.

La fórmula de la relación - esencial en todos los géneros dramáticos auriseculares - no podía faltar. Baste el ejemplo de la disparatada de Rosicler en latín macarrónico (vv. 1796 y ss.):

\begin{tabular}{|c|c|}
\hline Rosicler & $\begin{array}{l}\text { Pues si es viejo el ser romance, } \\
\text { ¿hay más de que sea latín? } \\
\text { In Trapobana mea patria } \\
\text { Rex illustris natus fui, } \\
\text { et amor unam sagittam } \\
\text { tiravit mihi, vel mi. } \\
\text { Non sagitta fuit vulgaris, } \\
\text { attamen sagitta fuit } \\
\text { quae penetravit ad almam, } \\
\text { cum verbo illo volo, vis. } \\
\text { Vidi calceamentum unum } \\
\text { Phyllidis... }\end{array}$ \\
\hline
\end{tabular}

Las escenas de jardín, y los sueños fingidos de la dama (vv. 343 y ss.; 627 y ss.) parodian las correspondientes del género de capa y espada y el palatino ${ }^{42}$. Tirso es especialmente aficionado a este recurso de un personaje que finge dormir para así poder confesar libremente

41 La lectura de Íñiguez, 2001, p. 191, que piensa que esta gruta es un espacio subterráneo donde se desarrolla parte de la acción, y que contiene al mar y a la tierra, es equivocada.

${ }^{42}$ Si la escena se coloca en otros géneros, como hagiográfico o bíblico — caso de dos citadas de Tirso - corresponde a la subtrama amorosa. 
su amor (El vergonzoso en palacio, La mujer que manda en casa, La mejor espigadera).

El desmayo de la dama que ocurre a Pocris, en una elaborada situación cómica, es otra fórmula habitual en las tramas amorosas de las comedias caballerescas y mitológicas como Apolo y Climene (pp. 1847, 1851) o El monstruo de los jardines (p. 1992):

POCRIS

Mal de mi aliento me valgo,

que al veros, de asombro llena,

¡qué horror!, ¡qué espanto!, ¡qué pena!

si me diérades lugar,

me quisiera desmayar.

Desmáyase.

CÉfalo Desmayaos en hora buena.

FILIS ¿Desmayose esa señora?

Céfalo Sí.

Filis Pues si se desmayó,

quiero ahora despertar yo. (vv. 720-728)

A la parodia de los dramas de poder y de ambición, insertos en el marco del tema del buen gobierno corresponden muchas intervenciones del rey (vv. 854 y ss. "Qué grande carga es reinar») y su privado Antistes (vv. 990-991 «Las palabras de los reyes / son balas de pieza gruesa»). El discurso del rey astrólogo (evocador del Basilio de La vida es sueño, y otros como Admeto de Apolo y Climene) es otro pasaje que remite a este tipo de comedia de implicaciones políticas y morales. Es relevante en especial la arenga de los vv. 1450 y ss. ("Vasallos, deudos y amigos») donde explica los agüeros nefastos que ha leído en las estrellas y que le han impulsado a encerrar a sus hijas, y que deriva en una enumeración culinaria según la estructura típica de disparates (vv. 1530 y ss.):

las hice de cal y canto

ese dorado ataúd;

porque, en fin, es menor daño

de mis desdichas y sus

influjos que mueran vivas,

que no que en mi senectud, 


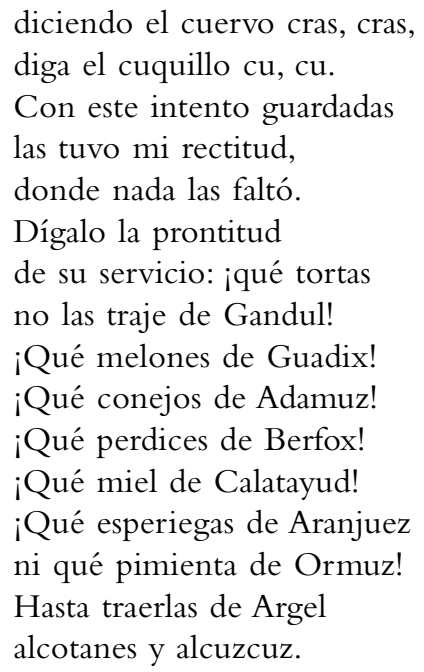

Los dramas de honor son el modelo de escenas como la de Antistes y Aura (vv. 993 y ss), en la que el padre da a elegir a la hija deshonrada si muere por puñal o veneno (se reconoce en el motivo del frasco de veneno la parodia del objeto patético que es frecuente en la tragedia senequista anterior al triunfo de la comedia nueva):

Aura Hame dado una palabra.

Antistes ¿Qué te ha quitado por ella?

Aura

ANTISTES

Aura

ANTISTES

Solo el honor.

¿No más?

$$
\text { No. }
$$

Me cautiva esa modestia, que si hubiera hecho contigo alguna cosa mal hecha, ¡vive Dios! que hiciera... Pero ¿qué sé yo lo que me hiciera? $\mathrm{Y}$ así, aunque indignado estaba, tanto mi cólera templas, que te he de dar a escoger si quieres morir con esta daga o con este veneno.

Aura

Antistes ¿Dónde está? 
Aura

AnTISTES

Aura

ANTISTES

Aura
¿Tan prevenido venías?

¿Qué padre que honor sustenta

y tiene sangre en el ojo, pelo en pecho y canas peina, puede andar sin un veneno, teniendo una hija doncella, que la pesa al serlo tanto, que parece que se huelga? Padre, señor, yo... si... cuando...

No me hagas ya pataletas, ni carantoñas, ni esguinces, sino escoge, como en peras, en muertes. Dime, pues, ¿qué te agrada?

Ninguna dellas, porque ninguna es airosa.

No hace falta elaborar la parodia para otros géneros teatrales o parateatrales que se integran en Céfalo, puesto que ya pertenecen en sí mismos a los géneros cómicos y propios de carnaval $^{43}$ y basta insertarlos en la pieza: juegos escenificados como la gallina ciega o el correr de los gallos, las mojigangas, los mimos de matachines o el baile del guineo (vv. 2321 y ss.):

Canta [el rey]. Vaya, vaya de mojiganga, de alegría y de pesar; que quien llora con placer, siente bien cualquiera mal.

TODA LA Mús. Vaya, vaya de mojiganga de alegría y de pesar; que quien llora con placer, siente bien cualquiera mal.

Rey Canta. El Gigante con las dueñas salga el guineo a bailar.

Salen las Dueñas y el Gigante.

DuEÑas Mejor fuera una endiablada.

${ }^{43}$ Ver para los aspectos más carnavalescos, González, 1978. 
REY

Pues bailen con Barrabás.

Salen todos.

ToDos

Para eso, bailemos todos.

REY

TODOS

Pues repitan a compás...

Vaya, vaya de mojiganga, de alegría y de pesar; que quien llora con placer, siente bien cualquiera mal.

Hacen un torneo en forma de matachines, $y$ dan fin.

En su conjunto, pues, se ofrece Céfalo y Pocris, como un complejo muestrario de parodias genéricas y de modelos teatrales carnavalescos, sin que se pueda considerar parodia de un modelo concreto como Celos aun del aire matan o Auristela y Lisidante.

\section{A modo de conclusión}

En varias ocasiones ha planteado la crítica el sentido final de estas comedias burlescas y juegos disparatados, preguntándose si revisten crítica o son mera diversión ${ }^{44}$. En particular a propósito de Céfalo, Íñiguez Barrena ${ }^{45}$ insiste en que hay una crítica del rey y de sus ministros, crítica fortísima, una «clara crítica de las intrigas y asechanzas palaciegas que Calderón dirige al público», en la que el reino de Tinaja sería alusión a España y a la oquedad de la vida y la política española, y en la que «Calderón pretende mostrar a los espectadores - el rey y sus consejeros - sus propias caricaturas para ver si reaccionan y cogen las riendas del gobierno de España». Estas aseveraciones serían muy dificiles de demostrar, sobre todo si se tiene en cuenta la lectura constantemente errada que hace Íñiguez de muchos aspectos de la comedia (cree por ejemplo que los actores son la misma familia real y los grandes de la corte, que se suenan con los dedos, hacen chistes escatológicos y se repelan los moños). Es inverosímil a mi juicio que un género que servía de diversión a la corte en los días de carnaval, como

${ }^{44}$ De dos excelentes conocedores del género, Serralta, por ejemplo (1980), se inclina por una interpretación eminentemente jocosa, mientras García Lorenzo (1977) defiende un valor crítico.

45 Íñiguez Barrena, 2001, pp. 191-195. 
es el de las comedias burlescas, pretendiera una crítica al rey o sus ministros. Más bien pertenecería, como el entremés, y otros modelos del disparate, al reino que llamaba Asensio de las vacaciones morales, de la chanza y del ingenio.

Algunas citas calderonianas, en fin, sobre la función y requisitos del disparatar, pueden servir de orientación para la lectura del Céfalo y los otros casos que se han comentado en estas páginas:

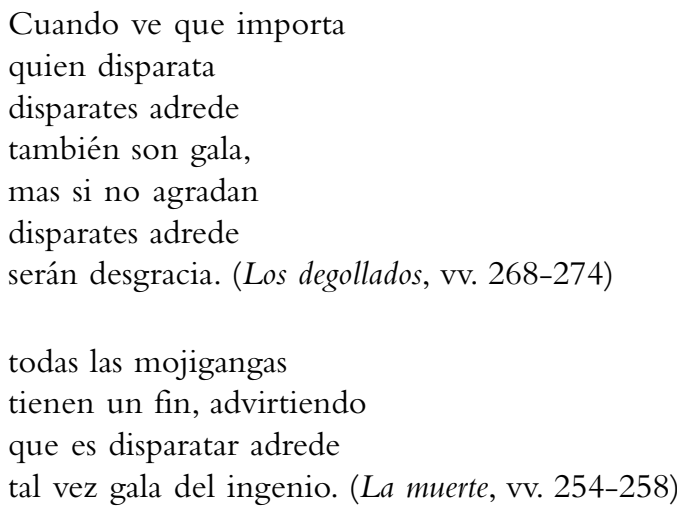

Este me parece que es el objetivo de los disparates de Calderón: divertir haciendo gala de su habilidad poética, capaz de las reflexiones más serias, de las tragedias más melancólicas, y de los disparates adrede más ingeniosos. 


\section{Bibliografía}

Academia burlesca que se hizo en el Buen Retiro a la majestad de Filipo Cuarto, ed. M. T. Julio, Madrid / Frankfurt, Iberoamericana / Vervuert, 2007.

Arellano, I., "Calderón y Cervantes», Hacia Calderón (V Coloquio anglogermano), ed. H. Flasche y R. D. F. Pring-Mill, Wiesbaden, Franz Steiner, 1982, pp. 9-19.

— «La comicidad escénica en Calderón», Bulletin Hispanique, 88, 1986, pp. 47-92.

- «Cervantes en Calderón», Anales cervantinos, 35, 1999, pp. 9-35.

- «La Celestina en la comedia del XVII», en Celestina: recepción y herencia de un mito literario, ed. G. Torres, Cáceres, U. de Extremadura, 2001, pp. 51-72, y en La Celestina. V Centenario. Actas del Congreso Internacional, Cuenca, Universidad de Castilla-La Mancha, 2001, pp. 247-268.

- «Literatura sin libro: literatura de repente y oralidad en el Siglo de Oro», en Pulchre, bene, recte. Estudios en homenaje al prof. Fernando González Ollé, Pamplona, Eunsa, 2002, pp. 101-119.

- «Mascaradas quijotescas», Pliegos volanderos del GRISO, 8, septiembre 2005. 35 pp. Y en Leyendo el Quijote, volumen especial de Príncipe de Viana, 236, 2005a, pp. 947-961.

- «La escenificación de la comedia burlesca», en Escenografía y escenificación en el tea tro español del Siglo de Oro, ed. R. Castilla y M. González Dengra, Granada, Universidad de Granada, 2005b, pp. 7-56.

Borrego, E., «Música y versos musicales en una comedia burlesca de Calderón», en Calderón 2000, ed. I. Arellano, Kassel, Reichenberger, 2002, pp. 971-986.

Calderón de la Barca, P., Amado y aborrecido, en Obras completas, tomo I, Dramas, ed. Á. Valbuena Briones, Madrid, Aguilar, 1987.

- Antes que todo es mi dama, en Obras completas, tomo II, Comedias, ed. Á. Valbuena Briones, Madrid, Aguilar, 1973.

- Apolo y Climene, en Obras completas, tomo I, Dramas, ed. Á. Valbuena Briones, Madrid, Aguilar, 1987.

- Auristela y Lisidante, ed. R. Arana, en prensa.

- Céfalo y Pocris, en Comedias burlescas del Siglo de Oro, ed. I. Arellano et al., Madrid, Espasa Calpe, 1999.

- Celos aun del aire matan, ed. E. Rull, Madrid, UNED, 2004.

- Duelos de amor y lealtad, en Obras completas, tomo I, Dramas, ed. Á.Valbuena Briones, Madrid, Aguilar, 1987.

- El golfo de las sirenas, en Obras completas, tomo I, Dramas, ed. Á. Valbuena Briones, Madrid, Aguilar, 1987.

- El hijo del Sol, Faetón, en Obras completas, tomo I, Dramas, ed. Á. Valbuena Briones, Madrid, Aguilar, 1987.

- El mayor encanto amor, en Obras completas, tomo I, Dramas, ed. Á. Valbuena Briones, Madrid, Aguilar, 1987.

- El monstruo de los jardines, en Obras completas, tomo I, Dramas, ed. Á.Valbuena Briones, Madrid, Aguilar, 1987.

- Fortunas de Andrómeda y Perseo, en Obras completas, tomo I, Dramas, ed. Á.Valbuena Briones, Madrid, Aguilar, 1987. 
- Judas Macabeo, en Obras completas, tomo I, Dramas, ed. Á.Valbuena Briones, Madrid, Aguilar, 1987.

- La fiera, el rayo y la piedra, en Obras completas, tomo I, Dramas, ed. Á.Valbuena Briones, Madrid, Aguilar, 1987.

- La púrpura de la rosa, en Obras completas, tomo I, Dramas, ed. Á. Valbuena Briones, Madrid, Aguilar, 1987.

- Ni Amor se libra de amor, en Obras completas, tomo I, Dramas, ed. Á.Valbuena Briones, Madrid, Aguilar, 1987.

- Novena Parte de comedias del célebre poeta español, Don Pedro Calderón de la Barca [...] que nuevamente corregidas publica Don Juan de Vera Tassis y Villarroel [...], en Madrid, por Francisco Sanz [...], año de 1691.

- Teatro cómico breve, ed. M. L. Lobato, Kassel, Reichenberger, 1989.

Chaves, T., El espectáculo teatral en la corte de Felipe IV, Madrid, Ayuntamiento, 2004.

Chevalier, M., "Cuentecillos y chistes tradicionales en la obra de Quevedo», Nueva Revista de Filología Hispánica, 25, 1976, pp. 17-44.

Cotarelo, E., Ensayo sobre la vida y obras de D. Pedro Calderón de la Barca, Madrid, Rev. de Archivos, Bibliotecas y Museos, 1924. Ed. facsímil de I. Arellano y J. M. Escudero, Madrid / Frankfurt, Iberoamericana / Vervuert, 2001.

DICAT, Diccionario biográfico de actores del teatro español, dir. T. Ferrer, Kassel, Reichenberger, 2008.

García Lorenzo, L., "La comedia burlesca en el siglo XviI. Las mocedades del Cid de Jerónimo de Cáncer», Segismundo, 25-26, 1977, pp. 131-146.

García Valdés, C. C., "Técnicas escénicas y verbales en Céfalo y Pocris», en Calderón: sistema dramático y técnicas escénicas, ed. F. Pedraza, R. González Cañal y E. Marcello, Almagro, Universidad de Castilla-La Mancha, 2001, pp. 253-269.

GonzÁlez, E., "Carnival on the Stage: Céfalo y Pocris, comedia burlesca», Bulletin of the Comediantes, 30, 1978, pp. 3-12.

Granja, A. de la, «Semblanza de don Pedro Calderón y autorretrato en cómico estilo", El siglo que viene, 41-42, junio, 2000, pp. 21-27.

- «Un temprano romance burlesco de Calderón», en Giornate calderoniane, ed. E. Cancelliere, Palermo, Flaccovio, 2003, pp. 63-85.

Íñiguez Barrena, F. «Técnicas dramáticas en Céfalo y Pocris, de Pedro Calderón de la Barca», en Actas del VIII Simposio de la Asociación de Profesores de Español, Pamplona, Asociación de Profesores de Español de Navarra, 2001, pp. 189-196.

KenNedy, R. L., «Escarramán and Glimpses of the Spanish Court in 1637-38», Hispanic Review, 9, 1941, pp. 111-136.

Lacadena, E., «El discurso oral en las academias del Siglo de Oro», Criticón, 41, 1988, pp. 87-102.

Lobato, M. L., «El Quijote en las mascaradas populares del siglo XVII», en Cervantes. Estudios reunidos en la víspera de su centenario, Kassel, Reichenberger, 1994, vol. II, pp. 577-604.

López Estrada, F., «Fiestas y literatura en los Siglos de Oro. La Edad Media como asunto festivo (El caso del Quijote)", Bulletin Hispanique, 84, 1982, pp. 291-327.

Navarro, A., Calderón de la Barca: de lo trágico a lo grotesco, Kassel, Reichenberger, 1984.

Periñán, B., Poeta ludens, Pisa, Giardini, 1979. 
Pinillos, M. C., «Intertextualidad y reescritura paródica en la comedia burlescas: Céfalo y Pocris, de Calderón», en Calderón 2000, ed. I. Arellano, Kassel, Reichenberger, 2002, pp. 1107-1116.

Pinto, E. di, «Los mecanismos de la risa: de Auristela y Lisidante y Celos aun del aire matan, a Céfalo y Pocris», en Calderón 2000, ed. I. Arellano, Kassel, Reichenberger, 2002, pp. 997-1006.

Rodríguez Villa, A., La corte y la monarquía de España, Madrid, s. e., 1886.

SÁnchez, A., "Reminiscencias cervantinas en el teatro de Calderón», Anales cervantinos, 6, 1957, pp. 262-270.

Serralta, F., «La comedia burlesca: datos y orientaciones», en Risa y sociedad en el teatro español del Siglo de Oro, Toulouse, CNRS, 1980, pp. 99-114.

Torres, L., «Las fiestas paródicas en la corte de Valladolid a través de las relaciones de sucesos», en La fiesta, ed. S. López Poza y N. Peña, La Coruña, Sociedad de Cultura «Valle Inclán», 1999, pp. 339-350. 